PATIENT WITH CJD TO RECEIVE PIONEERING TREATMENT

According to a variety of news sources last month, a judge at the Court of Protection has given the go-ahead for the pioneering treatment of a man dying with Creutzfeldt-Jakob disease (CJD). Until now there has been no treatment for CJD - the human variant of bovine spongiform encephalopathy (BSE), known as 'mad cow disease'

There is no evidence of vCJD being transmitted through clinical dental practice or from human to human. Nevertheless, after the 1990s BSE outbreak in the UK, decontamination procedures were dramatically stepped up.

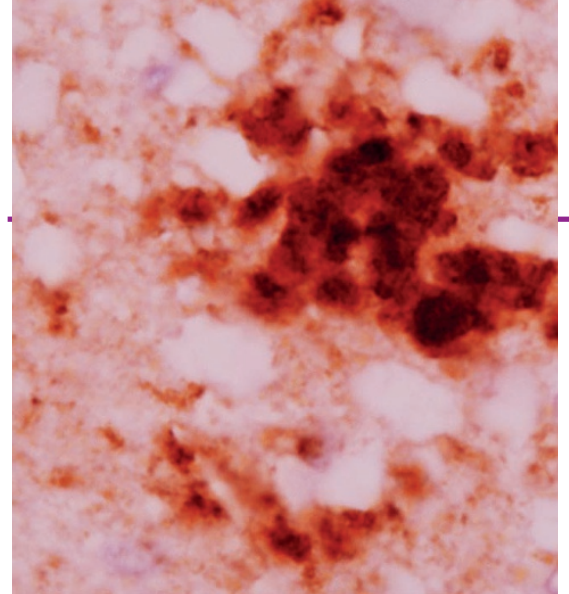

The disease is rare but fatal, usually killing patients within six weeks. Scientists at University College London's Prion Unit, which was established by the Government in the wake of the 1990s BSE outbreak, have spent 20 years working on the treatment. Called PRN100 - it's a synthetic antibody they hope will stop CJD attacking the brain. Laboratory tests have been encouraging but until now no human has received the treatment.

\title{
BRILLIANT BRUSH DJ WOWS BSPD - NOW OUTSTANDING INNOVATION AWARD OPEN FOR 2019 ENTRIES
}

The British Society of Paediatric Dentistry's Outstanding Innovation Award is open for entries. The award, now in its second year, was established to give recognition to shining examples of initiatives which improve children's oral health. The winner in 2018 was dentist Ben Underwood for his tooth-brushing app BrushDJ. The first prize for the award is the opportunity to speak at BSPD's conference and Ben's presentation was definitely a highlight of the Dundee gathering.

He outlined the background to the development of the app which has now been downloaded in 199 countries. When he first suggested to colleagues, he said, that he might have devised an innovation which would inspire improved tooth brushing, he was looked at with disbelief.

With the majority of people owning Smart phones, however, he was confident that mobile phone use would continue to accelerate and a free app with music could potentially have universal appeal.

Not only is it a brilliant idea, he has made it accessible to all including blind or low vision users and those with dyslexia. And by making it free and available on any kind of phone, it's affordable to those in deprived communities who are hardest to reach.
As the

music is taken from the user's phone, its appeal spans all ages and cultures. 'If you want to make people do something, he said, 'you have to make it fun.'

Ben was

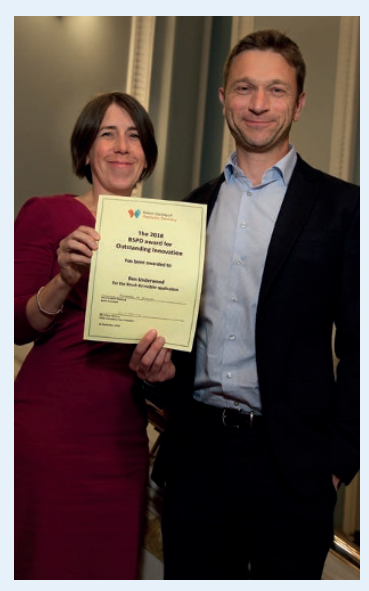

an inaugural

NHS Innovation Accelerator Fellow and BrushDJ is the only dental app in the NHS digital library. It has won multiple awards and he continues to evolve content and extend access to free music.

The first winner of the award in 2017 was Teeth Team and Ingrid Perry, the secretary of the Hull-based charity spoke at last year's conference. Entries for the 2019 award can be on paper or in electronic or poster format and there is no word limit. Pictures which illustrate the project are welcome but not essential. The key test is that the project benefits children or young people who may be at risk of dental decay. https://www.bspd. co.uk/Professionals/Awards-and-Prizes/

\section{First DCbyI \\ Practice of the Year named as The Maltings}

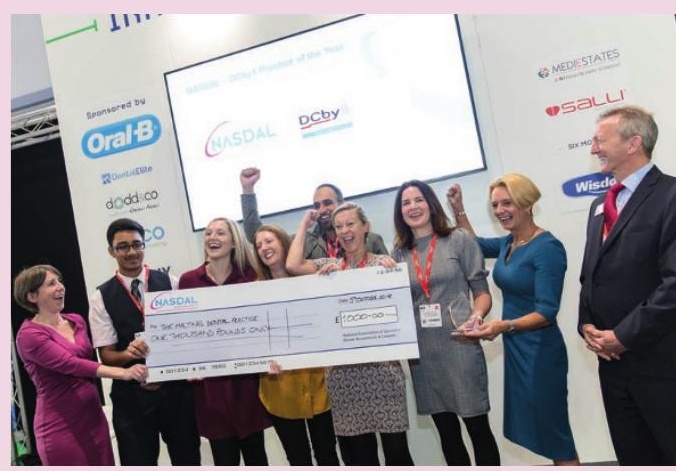

The Maltings Dental Practice in

Grantham, Lincolnshire are the winners of the inaugural NASDAL (The Association of Specialist Dental Accountants and Lawyers) Dental Check by One Practice of the Year Award. Five team members were at BDIA Showcase to collect a cheque for $£ 1000$.

The award has been created by NASDAL to recognise the efforts that practices up and down the country are putting into the British Society of Paediatric Dentistry (BSPD) Dental Check by One campaign. The aim of the DCbyl campaign is to increase the number of children who access dental care aged $0-2$ years.

Louise Butler, Practice Manager at The Maltings Dental Practice said on behalf of owner dentist Jason Wong: 'We are delighted to win this award - the whole team work so hard and to receive this kind of recognition will really spur the team on to further efforts.'

Nick Ledingham, Chairman of NASDAL, commented, 'NASDAL has always been keen to recognise business excellence in dentistry but in addition, this new award has illustrated that doing the right thing makes good business sense too. Congratulations to The Maltings Dental Practice who were worthy winners.'

Claire Stevens, President of BSPD, added, I am delighted that Jason Wong and his team at the Maltings Dental Practice are the winners of the NASDAL DCbyl Practice of the Year award. Their commitment to the campaign has been outstanding and this award is well deserved. They are a great example of what can be achieved and we hope to see more inspiring entries into the award next year.' 